\title{
Pharmacologic treatment and SUDEP risk
}

\section{A nationwide, population-based, case-control study}

Olafur Sveinsson, MD, PhD, Tomas Andersson, BSc, Peter Mattsson, MD, PhD, Sofia Carlsson, PhD, and Torbjörn Tomson, MD, PhD

Neurology ${ }^{\circledR}$ 2020;95:e2509-e2518. doi:10.1212/WNL.0000000000010874

\section{Abstract}

\section{Objective}

We conducted a nationwide case-control study in Sweden to test the hypothesis that antiepileptic drugs (AEDs) mono- or polytherapy, adherence, antidepressants, neuroleptics, $\beta$-blockers, and statins are associated with sudden unexpected death in epilepsy (SUDEP) risk.

\section{Methods}

Included were 255 SUDEP cases and 1,148 matched controls. Information on clinical factors and medications came from medical records and the National Patient and Prescription Registers. The association between SUDEP and medications was assessed by odds ratios (ORs) with 95\% confidence intervals (CIs) adjusted for potential risk factors including type of epilepsy, living conditions, comorbidity, and frequency of generalized tonic-clonic seizures (GTCS).

\section{Results}

Polytherapy, especially taking 3 or more AEDs, was associated with a substantially reduced risk of SUDEP (OR 0.31, 95\% CI 0.14-0.67). Combinations including lamotrigine (OR 0.55, 95\% CI 0.31-0.97), valproic acid (OR 0.53, 95\% CI 0.29-0.98), and levetiracetam (OR 0.49, 95\% CI 0.27-0.90) were associated with reduced risk. No specific AED was associated with increased risk. Regarding monotherapy, although numbers were limited, the lowest SUDEP risk was seen in users of levetiracetam $(0.10,95 \%$ CI $0.02-0.61)$. Having nonadherence mentioned in the medical record was associated with an OR of 2.75 (95\% CI 1.58-4.78). Statin use was associated with a reduced SUDEP risk (OR 0.34, 95\% CI 0.11-0.99) but selective serotonin reuptake inhibitor use was not.

\section{Conclusion}

These results provide support for the importance of medication adherence and intensified AED treatment for patients with poorly controlled GTCS in the effort to reduce SUDEP risk and suggest that comedication with statins may reduce risk.

\author{
Correspondence \\ Dr. Sveinsson \\ olafur.sveinsson@sll.se
}

\section{RELATED ARTICLE}

\section{Editorial}

Reducing the risk of SUDEP: From uncertainty to reality

Page 807

\section{MORE ONLINE}

\section{- CME Course}

NPub.org/cmelist 


\section{Glossary}

AED = antiepileptic drug; ATC $=$ Anatomical Therapeutic Chemical; $\mathbf{C I}=$ confidence interval; GTCS $=$ generalized tonicclonic seizure; ICD = International Classification of Diseases; OR = odds ratio; SAS = Statistical Analysis Software; SNPR = Swedish National Patient Register; SSRI = selective serotonin reuptake inhibitor; SUDEP $=$ sudden unexpected death in epilepsy.

There is an urgent need to reduce the risk of sudden unexpected death in epilepsy (SUDEP). ${ }^{1}$ Risk factors related to drug treatment may represent opportunities for prevention. Data on antiepileptic drugs (AEDs) and SUDEP risk are limited. ${ }^{2}$ Carbamazepine $e^{3,4}$ and lamotrigine ${ }^{5}$ have been reported to increase the risk, observations not confirmed when adjustments were made for generalized tonic-clonic seizures (GTCS). ${ }^{6,7}$ Polytherapy with AEDs was a risk factor in some studies ${ }^{8,9}$ but not in a meta-analysis controlling for GTCS. $^{7}$ Adding an AED rather than placebo to existing AED medication was associated with a lower SUDEP incidence in a meta-analysis of randomized controlled trials in refractory epilepsy. ${ }^{10}$ Nonadherence to AED treatment has been associated with increased mortality, ${ }^{11,12}$ although SUDEP risk has not been analyzed. Other drugs have been discussed in relation to SUDEP. Antidepressants have been proposed to potentially reduce SUDEP risk based on animal data, ${ }^{13}$ but clinical data are lacking. In the absence of large clinical trials, observational data can provide important insights on the potential role of drugs in the prevention of SUDEP. In order for such results to be valid, it is crucial to adjust for other potential risk factors for SUDEP that may differ across treatment groups.

We carried out a population-based case-control study in Sweden to assess the association between use of AEDs, selective serotonin reuptake inhibitors (SSRIs), and other potentially relevant drugs and SUDEP risk utilizing a combination of data from individual medical records, providing detailed information on potential confounders, and national registries including specific data on drug exposure.

\section{Methods}

We have used the same cases and controls as in a recent analysis of clinical risk factors for SUDEP and the methods for identification of the cases and controls have been described in detail. $^{14}$

\section{SUDEP definition and classification}

SUDEP is defined as sudden, unexpected, witnessed or unwitnessed, nontraumatic, and nondrowning death of patients with epilepsy with or without evidence of a seizure, excluding documented status epilepticus, and in whom postmortem examination does not reveal a structural or toxicologic cause for death. ${ }^{15}$ To facilitate comparison with previous studies, we classified SUDEP cases according to Annegers ${ }^{16}$ criteria into definite, probable, or possible.

\section{Study population}

Together with each individual's personal identification number, the Swedish National Patient Register (SNPR) contains ICD codes for all patients hospitalized (starting in 1968, with total national coverage from 1987) or managed in hospital-based ambulatory care since $2001 .{ }^{17}$ Our study population was composed of all individuals who were registered at any time during 1998-2005 in the SNPR with an ICD-10 code for epilepsy (G $40)(\mathrm{n}=78,424)$ who were alive on June 30, $2006(\mathrm{n}=60,952)$.

\section{Cases}

Using linkage to the National Cause of Death Registry (ICD-10 classified since 1994), ${ }^{18} 9,605$ deaths were identified from the study population during the follow-up time from July 1,2006 , to December 31, 2011. All deaths with epilepsy written on the death certificate $(\mathrm{n}=1,276)$, together will all individuals who died during 2008 ( $\mathrm{n}=1,890)$, were eligible SUDEP cases (figure 1). One neurologist (O.S.) reviewed all death certificates. Excluded from further analysis of case records were obvious non-SUDEP deaths such as malignancy, terminal illness, stroke, myocardial infarct, and postmortem confirmed pneumonia (figure 1). For the remaining cases $(n=1,373)$, where SUDEP could potentially be the cause of death, patient records from family physicians, hospital records, nursing homes or other institutions, police records, and autopsy records were reviewed (O.S.). Standardized protocol was used when information was extracted from records. Two neurologists (O.S. and T.T.) reviewed all gathered information and classification of cases was made through consensus. All cases had to meet the criteria for a diagnosis of epilepsy according to the definition of the International League Against Epilepsy. ${ }^{19}$ Finally, 255 definite $(\mathrm{n}=$ $167)$ and probable $(\mathrm{n}=88)$ cases according to the Annegers' classification served as cases for this study (figure 1). Possible SUDEP cases $(n=73)$ were not used for analysis in this study.

\section{Controls}

From the study population, 5 epilepsy controls $(n=1,275)$ for each SUDEP case, of the same sex, who were alive at the case's time of death were randomly selected by the National Board of Health and Welfare. The case's time of death served as an index date for the controls, who thus were matched with the cases for sex and calendar time. We acquired medical records for 1,232 (97\%) controls, of which 84 (6.8\%) were adjudicated not to have epilepsy after case review. The remaining 1,148 individuals served as controls in the current study (figure 1).

\section{Information from patient records}

Through patient records, we collected information on age, sex, and living conditions (living alone, with others, including parents, 


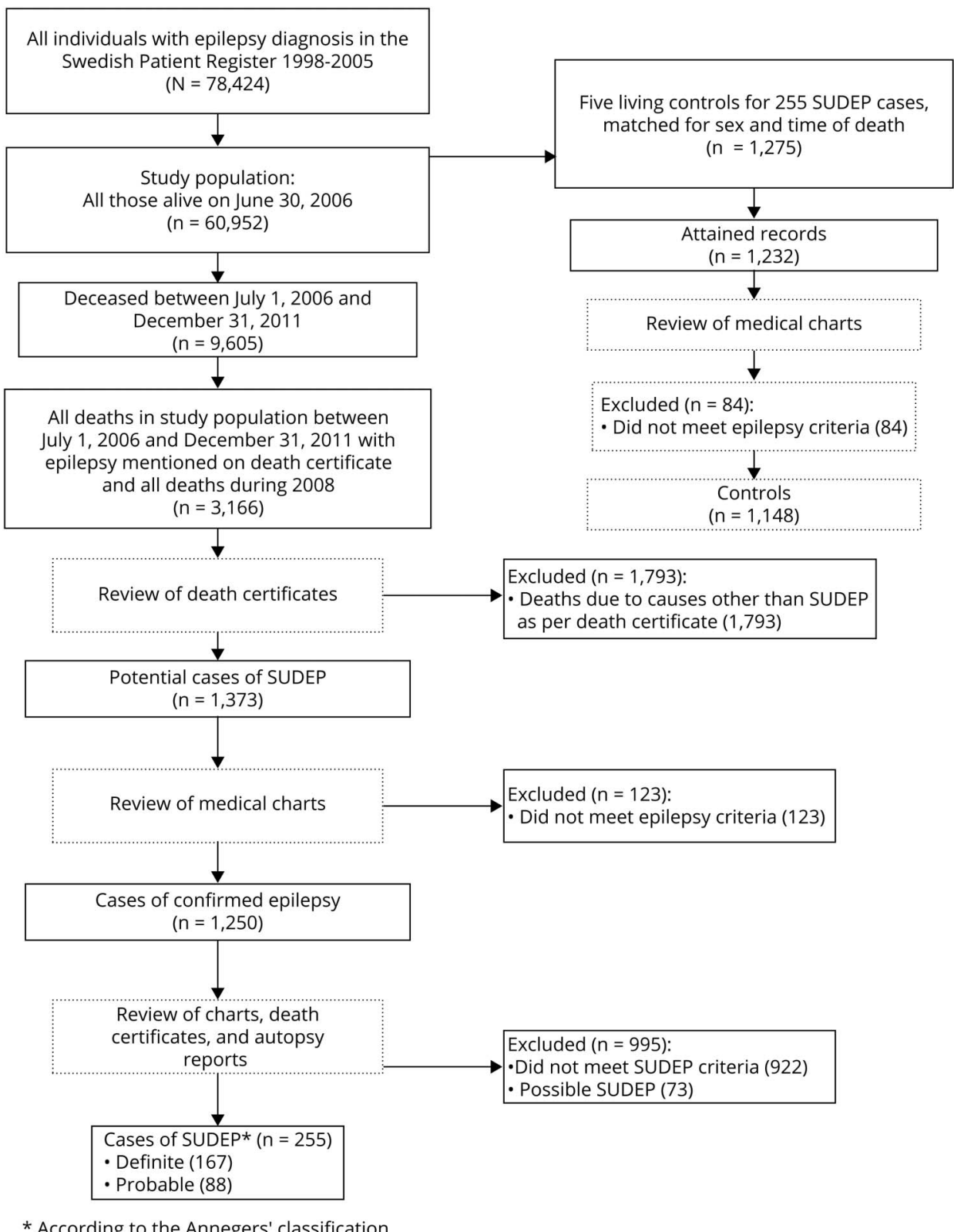

SUDEP = sudden unexpected death in epilepsy.

partners, children, siblings, and if sharing a bedroom) for all cases and controls. Individuals who were married or had a partner were classified as sharing a bedroom, if not otherwise explicitly stated. Further information was collected on epilepsy onset, duration of epilepsy, type of epilepsy, etiology, ${ }^{20}$ history of tonic-clonic seizures (in this context including both GTCS and focal to bilateral tonic-clonic seizures in accordance with most previous casecontrol studies of SUDEP, and abbreviated GTCS), ${ }^{19}$ presence and frequency of GTCSs during last year of observation, presence of other seizures during the last year of observation, history of nocturnal seizures, history of nocturnal GTCS, and presence of nocturnal GTCS during last year of observation. If nonadherence was mentioned in the 5 years leading up to death or index date, the patient was classified as nonadherent.

\section{Information from the Swedish Prescribed Drug Register}

We used the National Prescribed Drug Register to assess drug exposure. The Register records information on all prescribed drugs dispensed at Swedish pharmacies since July $2005 .^{21}$ Medications are classified according to Anatomical Therapeutic Chemical (ATC) classification system and in the present study, code ATC N03A was used for AEDs. For the current analysis, we focused on the 7 most frequently used AEDs among our cases and controls. Using data from this register, we classified AED usage in the following way: taking an AED: AED dispensed within 90 days of death or index date, because in Sweden, drug dispensing cannot be for longer than 90 days at a time; monotherapy: only 1 AED dispensed within 90 days of 
death or index date: polytherapy: 2 or more AEDs dispensed within 90 days of death or index date; not taking an AED: no AED dispensed within 360 days of death or index date; undetermined group: AED dispensed between 90 and 360 days but not within 90 days from death or index date. We also collected information on concomitant treatment with neuroleptics (ATC N05A), antidepressants (ATC N06A), $\beta$-blockers (ATC C07A), and statins (ATC C10A). Cases and controls were considered to use the above-mentioned medications if they had been dispensed within 90 days of death or index date.

\section{Information from the Swedish National Patient Registers}

Information on substance abuse and alcohol dependence was obtained from the SNPR (from 1997 to death or index date) as previously described ${ }^{14}$; information on intellectual disability was collected from patient records. Information on highest educational level was attained from the Longitudinal Integration Database for Health Insurance and Labor Market Studies (LISA), which holds registers since 1990 and includes all individuals 16-74 years of age.

\section{Statistics}

Characteristics were expressed as means (range) or proportions. The associations between SUDEP and medications were estimated by odds ratios (ORs) with $95 \%$ confidence intervals (CIs) calculated by conditional logistic regression to account for matching by sex and calendar time. As the control participants were sampled with an incidence density method, the ORs can be interpreted as incidence rate ratios. ${ }^{22}$ In model 1, ORs were adjusted for matching variables (sex and calendar time) and age. Model 2 included additional adjustments for duration and type of epilepsy, living conditions (sharing bedroom), intellectual disability, substance abuse, alcohol dependence, and education. Model 3 included the same covariates as model 2 together with history of GTCS, frequency of GTCS, and nocturnal GTCS during last year of observation, which was included separately because they were considered potential mediators of the association between treatment and SUDEP. In the Results, results from model 3 are presented unless stated otherwise. In a post hoc analysis, we assessed the impact of the level of care by adding this covariate to those included in model 3. For this purpose, we defined 3 levels where the highest was patients who had been subject to epilepsy surgery or vagus nerve stimulation treatment, which is only provided in tertiary epilepsy centers. The second level was those receiving care through neurologists or neuro-pediatricians, and the third level those not receiving their epilepsy care from such specialists. The latter information was obtained from the SNPR. Statistical Analysis Software (SAS) 9.4 (SAS Institute, Cary, NC) was used for all analyses.

\section{Standard protocol approvals, registrations, and patient consents}

The study was approved by the Ethics Committee of Karolinska Institutet, which granted that individual informed consent was not required.

\section{Data availability}

Anonymized data will be shared by request from qualified investigators to the corresponding author.

\section{Results}

Characteristics of cases and controls by AED treatment (none, mono-, and polytherapy) are presented in table 1. As described in detail previously, ${ }^{14}$ cases had longer duration of epilepsy, and were more likely to have history of GTCS, presence of GTCS, and nocturnal GTCS during the preceding year, intellectual disability, and a history of substance abuse, and were less likely to share a bedroom compared to controls. Taking no AED was more common among controls (23.1\%) than cases (18.4\%) and the most frequently used AED overall was carbamazepine among cases (33.3\%) and lamotrigine (24.5\%) among the controls. From table 1 it is evident that individuals on polytherapy more often have a history of GTCS including nocturnal GTCS during the preceding year and are more likely to have intellectual disability than individuals without AED treatment.

Using no AED treatment as reference, polytherapy, especially taking 3 or more AEDs, was associated with a significantly reduced risk of SUDEP after adjusting for GTCS frequency and other covariates (table 2). Numbers were small in analyses of specific monotherapies and levetiracetam was the only AED that was associated with a significantly lower SUDEP risk when compared to no AED treatment (OR 0.10, 95\% CI 0.03-0.61). Lamotrigine, valproic acid, and levetiracetam were associated with a significantly reduced risk when used as part of polytherapy (figure 2). For all AEDs except levetiracetam, a trend was observed towards lower risk when used in polytherapy compared with monotherapy (figure 2). No monotherapy increased the risk for SUDEP (table 2 and figure 2). The pattern was similar in a sensitivity analysis including only cases and controls with a history of GTCS (results not shown). Adjustment for level of care did not change any of the associations reported in table 2 (results not shown). SUDEP risk in relation to lamotrigine use was analyzed separately for female participants and there was no indication of excess risk when used as mono- or polytherapy (table 3 ).

SUDEP risk was also calculated in relation to time since last dispensing of AEDs as a measure of persistence or adherence to AED medication. This analysis was restricted to individuals for whom medical records stated that AEDs were prescribed during the last year of observation. Using 0-90 days as reference, individuals with 181-365 days since last dispensing had an OR of 2.96 (95\% CI 0.46-18.86). Similarly, having nonadherence mentioned in the medical record was associated with an OR of 2.75 (95\% CI 1.58-4.78) (table 2).

Use of statins was associated with a reduced risk of SUDEP but we did not observe a reduced risk with SSRIs or other antidepressants, neuroleptics, or $\beta$-blockers (table 4). 


\begin{tabular}{|c|c|c|c|c|c|c|c|c|}
\hline & \multicolumn{4}{|l|}{ Cases } & \multicolumn{4}{|l|}{ Controls } \\
\hline & Total & No AEDs ${ }^{a}$ & Monotherapy ${ }^{\mathbf{b}}$ & Polytherapy $^{c}$ & Total & No AEDs ${ }^{a}$ & Monotherapy ${ }^{b}$ & Polytherapy \\
\hline Total & 255 & $46(18.4)$ & $113(44.3)$ & $96(37.6)$ & 1148 & $265(23.1)$ & $483(42.1)$ & $400(35.0)$ \\
\hline Age at diagnosis, y & $13(3,39)$ & $21(12,51)$ & $17(4,46)$ & $5(1,24)$ & $12(4,29)$ & $9(4,22)$ & $16(7,41)$ & $9(3,21)$ \\
\hline Duration, y & $19(9,37)$ & $12(7,27)$ & $17(9,31)$ & $30(14,46)$ & $15(9,27)$ & $10(8,16)$ & $14(8,25)$ & $21(12,36)$ \\
\hline Men & $154(60.4)$ & $33(71.7)$ & $65(57.5)$ & $56(58.3)$ & $680(59.2)$ & $170(64.2)$ & $274(56.7)$ & $236(59.0)$ \\
\hline Sharing bedroom & $32(12.5)$ & $6(13.0)$ & $17(15.0)$ & $9(9.4)$ & $391(34.1)$ & $77(29.1)$ & $179(37.1)$ & $135(33.8)$ \\
\hline Generalized epilepsy & $37(14.5)$ & $8(17.4)$ & $17(15.0)$ & $12(12.5)$ & $267(23.3)$ & $68(25.7)$ & $131(27.1)$ & $68(17.0)$ \\
\hline Focal epilepsy & $186(72.9)$ & $27(58.7)$ & $88(77.9)$ & $71(74.0)$ & $794(69.2)$ & $175(66.0)$ & $311(64.4)$ & $308(77.0)$ \\
\hline Generalized and focal epilepsy & $10(3.9)$ & $1(2.2)$ & $2(1.8)$ & $7(7.3)$ & $31(2.7)$ & $4(1.5)$ & $10(2.1)$ & $17(4.3)$ \\
\hline Intellectual disability & $97(38.0)$ & $7(15.2)$ & $36(31.9)$ & $54(56.3)$ & $323(28.1)$ & 44 (16.6) & $107(22.2)$ & $172(43.0)$ \\
\hline Substance abuse & $34(13.3)$ & $11(23.9)$ & $17(15.0)$ & $6(6.3)$ & $53(4.6)$ & $18(6.8)$ & $16(3.3)$ & $19(4.8)$ \\
\hline Alcohol dependence & $26(10.2)$ & $8(17.4)$ & $13(11.5)$ & $5(5.2)$ & $34(3.0)$ & $13(4.9)$ & $13(2.7)$ & $8(2.0)$ \\
\hline Primary school education & $143(56.1)$ & $23(50.0)$ & $59(52.2)$ & $61(63.5)$ & $621(54.1)$ & $152(57.4)$ & $223(46.2)$ & $246(61.5)$ \\
\hline History of GTCS & $251(98.4)$ & 44 (95.7) & $111(98.2)$ & $96(100.0)$ & $943(82.1)$ & $195(73.6)$ & $401(83.0)$ & $347(86.8)$ \\
\hline GTCS last year & $217(85.1)$ & $34(73.9)$ & $94(83.2)$ & $89(92.7)$ & $280(24.4)$ & $32(12.1)$ & $95(19.7)$ & $153(38.3)$ \\
\hline Nocturnal GTCS last year & $110(43.1)$ & $13(28.3)$ & $51(45.1)$ & $46(47.9)$ & $99(8.6)$ & $13(4.9)$ & $24(5.0)$ & $62(15.5)$ \\
\hline Carbamazepine & $85(33.3)$ & & $45(39.8)$ & $40(41.7)$ & $279(24.3)$ & & $130(26.9)$ & $149(37.3)$ \\
\hline Lamotrigine & $65(25.5)$ & & $27(23.9)$ & $38(39.6)$ & $281(24.5)$ & & $104(21.5)$ & $177(44.3)$ \\
\hline Valproic acid & $47(18.4)$ & & $17(15.0)$ & $30(31.3)$ & $279(24.3)$ & & $126(26.1)$ & $153(38.3)$ \\
\hline Levetiracetam & $30(11.8)$ & & $2(1.8)$ & $28(29.2)$ & $168(14.6)$ & & $26(5.4)$ & $142(35.5)$ \\
\hline Phenytoin & $29(11.4)$ & & $10(8.8)$ & 19 (19.8) & $99(8.6)$ & & $44(9.1)$ & 55 (13.8) \\
\hline Topiramate & $22(8.6)$ & & $2(1.8)$ & $20(20.8)$ & $65(5.7)$ & & $11(2.3)$ & $54(13.5)$ \\
\hline Oxcarbazepine & $7(2.7)$ & & $3(2.7)$ & $4(4.2)$ & $45(3.9)$ & & $17(3.5)$ & $28(7.0)$ \\
\hline \multicolumn{9}{|c|}{$\begin{array}{l}\text { Abbreviation: GTCS = generalized tonic-clonic seizures. } \\
\text { Values are median (Q1, Q3) or } n(\%) . \\
\text { a No AED dispensed within } 90 \text { days of death or index date. } \\
\text { b Only } 1 \text { AED dispensed within } 90 \text { days of death or index date. } \\
\text { c Two or more AEDs dispensed within } 90 \text { days of death or index date. } \\
\text { d Information collected from patient records. }\end{array}$} \\
\hline
\end{tabular}


Table 2 Odds ratio (OR) and 95\% confidence interval (Cl) of sudden unexpected death in epilepsy in relation to antiepileptic drugs (AEDs), time since last dispensed AED, and nonadherence as noted in medical records

\begin{tabular}{|c|c|c|c|c|c|}
\hline & Cases, $\mathbf{n}$ & Controls, $\mathrm{n}$ & Model $1^{\mathrm{a}}$ OR $(95 \% \mathrm{CI})$ & Model $2^{\mathrm{b}}$ OR $(95 \% \mathrm{Cl})$ & Model $3^{\mathrm{C}}$ OR $(95 \% \mathrm{Cl})$ \\
\hline \multicolumn{6}{|l|}{ AED therapy } \\
\hline No AEDs ${ }^{d}$ & 46 & 265 & 1 & 1 & 1 \\
\hline Monotherapy ${ }^{\mathrm{e}}$ & 113 & 483 & $1.15(0.79-1.69)$ & $1.03(0.67-1.57)$ & $0.79(0.44-1.41)$ \\
\hline Polytherapy ${ }^{f}$ & 96 & 400 & $1.24(0.83-1.84)$ & $0.90(0.57-1.42)$ & $0.48(0.26-0.90)$ \\
\hline 2 AEDs & 65 & 272 & $1.22(0.80-1.87)$ & $0.94(0.58-1.51)$ & $0.59(0.31-1.12)$ \\
\hline$\geq 3$ AEDs & 31 & 128 & $1.27(0.76-2.12)$ & $0.81(0.45-1.48)$ & $0.31(0.14-0.67)$ \\
\hline \multicolumn{6}{|l|}{ Monotherapies $^{\mathrm{g}}$} \\
\hline No AEDs & 46 & 265 & 1 & 1 & 1 \\
\hline Carbamazepine & 45 & 130 & $1.57(0.97-2.55)$ & $1.38(0.80-2.37)$ & $1.00(0.48-2.11)$ \\
\hline Lamotrigine & 27 & 104 & $1.39(0.81-2.40)$ & $1.42(0.79-2.57)$ & $0.93(0.41-2.12)$ \\
\hline Valproic acid & 17 & 126 & $0.71(0.39-1.29)$ & $0.62(0.32-1.19)$ & $0.52(0.20-1.30)$ \\
\hline Phenytoin & 10 & 44 & $0.96(0.45-2.07)$ & $0.76(0.32-1.83)$ & $0.56(0.17-1.88)$ \\
\hline Levetiracetam & 2 & 26 & $0.39(0.09-1.71)$ & $0.33(0.07-1.53)$ & $0.10(0.02-0.61)$ \\
\hline Oxcarbazepine & 3 & 17 & $0.98(0.27-3.61)$ & $0.83(0.20-3.34)$ & $0.58(0.09-3.69)$ \\
\hline Topiramate & 2 & 11 & $0.95(0.20-4.61)$ & $0.67(0.12-3.64)$ & $2.02(0.29-14.26)$ \\
\hline Other monotherapies & 7 & 25 & $1.61(0.66-3.94)$ & $1.39(0.52-3.74)$ & $1.32(0.39-4.53)$ \\
\hline \multicolumn{6}{|c|}{ Time since last dispensed AED, $d^{h}$} \\
\hline $0-90$ & 199 & 871 & 1 & 1 & 1 \\
\hline $91-180$ & 16 & 85 & $0.85(0.48-1.49)$ & $1.13(0.61-2.08)$ & $1.20(0.50-2.87)$ \\
\hline $181-365$ & 6 & 15 & $1.99(0.72-5.51)$ & $3.41(1.05-11.09)$ & $2.96(0.46-18.89)$ \\
\hline$>365$ & 14 & 33 & $1.92(0.99-3.71)$ & $2.42(1.14-5.14)$ & $2.25(0.73-6.90)$ \\
\hline
\end{tabular}

Nonadherence mentioned

in medical record

\begin{tabular}{llllll}
\hline No & 173 & 886 & 1 & 1 & 1 \\
\hline Yes & 62 & 118 & $2.47(1.73-3.54)$ & $2.56(1.70-3.84)$ & $2.75(1.58-4.78)$ \\
\hline
\end{tabular}

Abbreviation: GTCS = generalized tonic-clonic seizures.

a Model 1 is adjusted for matching variables (sex and calendar time) and age.

${ }^{\mathrm{b}}$ Model 2 is adjusted for the same variables as model 1 together with duration and type of epilepsy, living conditions (sharing bedroom), intellectual disability, substance abuse, alcohol dependence, and education level.

' Model 3 is adjusted for the same variables as model 2 together with history of GTCS, GTCS frequency last year of observation, and nocturnal GTCS last year of observation.

${ }^{\mathrm{d}}$ No AEDs dispensed within 90 days of death or index date.

e Only 1 AED dispensed within 90 days of death or index date.

${ }^{\mathrm{f}}$ Two or more AEDs dispensed within 90 days of death or index date.

${ }^{\mathrm{g}}$ Seven most common monotherapies.

$\mathrm{h}$ Restricted to individuals prescribed AEDs according to patient records.

\section{Discussion}

In this population-based case-control study, we found that polytherapy with 3 or more AEDs was associated with a reduction of SUDEP risk by two-thirds after taking GTCS into account. We found no indications of an increased SUDEP risk with any of the investigated AEDs whether in mono- or polytherapy when adjustments were made for GTCS frequency and other covariates.
Out of the different AEDs used in monotherapy, the lowest SUDEP risk was seen in users of levetiracetam. AED polytherapy in general and more specifically in combinations including lamotrigine, valproic acid, and levetiracetam was associated with significantly reduced risks. Patients with a record of poor adherence had an increased SUDEP risk. Regarding other medications than AEDs, the only association was seen with statins, which appeared to be associated with a reduced SUDEP risk. 
Figure 2 Forest plot showing odds ratio and 95\% confidence interval $(\mathrm{Cl})$ of sudden unexpected death in epilepsy in relation to specific antiepileptic drugs (AEDs) as mono- and polytherapy (reference is individuals not on that AED, based on model 3)

\section{AED treatment}

Carbamazepine (N03AF01)

Monotherapy

Polytherapy

Lamotrigine (N03AX09)

Monotherapy

Polytherapy

Valproic acid (N03AG01)

Monotherapy

Polytherapy

Phenytoin (N03AB02)

Monotherapy

Polytherapy

Levetiracetam (N03AX14)

Monotherapy

Polytherapy

Oxcarbazepine (N03AF02)

Monotherapy

Polytherapy

Topirimate (N03AX11)

Monotherapy

Polytherapy

\section{Odds ratio $(95 \% \mathrm{Cl})$}

$1.64(0.89-3.03)$

$0.88(0.50-1.52)$

$1.34(0.67-2.66)$

$0.55(0.31-0.97)$

$0.66(0.29-1.50)$

$0.53(0.29-0.98)$

$0.84(0.28-2.47)$

$0.78(0.35-1.72)$

$0.14(0.02-0.79)$

$0.49(0.27-0.90)$

$0.85(0.15-4.75)$

$0.62(0.18-2.17)$

$3.32(0.55-19.93)$

$1.26(0.61-2.63)$

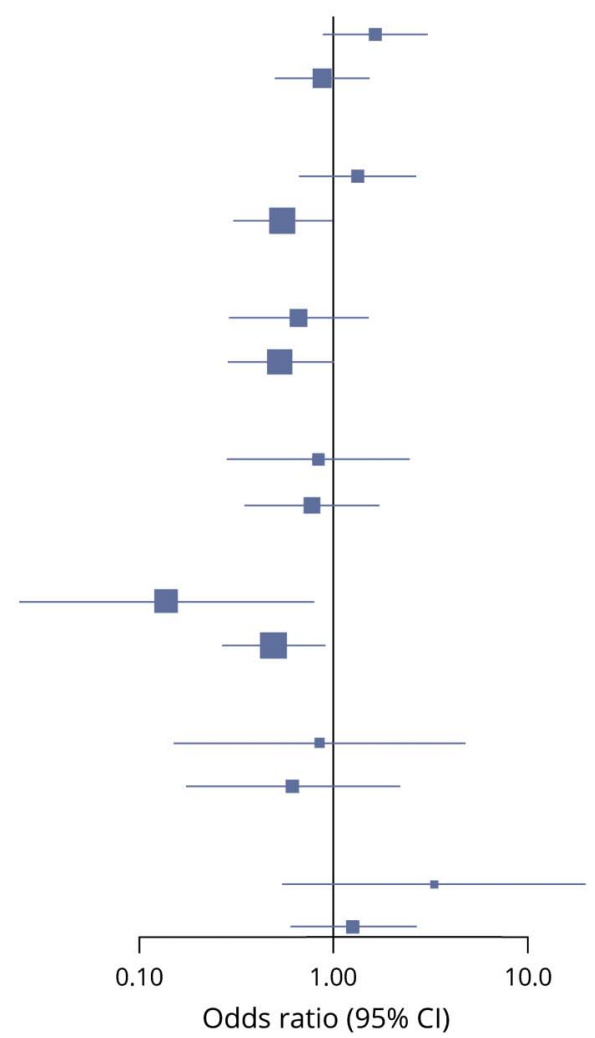

Our observations of a potential protective effect of AED polytherapy are in contrast to previous findings. In fact, 2 early case-control studies reported increased SUDEP risk with polytherapy as compared to monotherapy. ${ }^{8,9}$ Similar findings were reported in the pooled analysis of 3 case-control studies. However, because polytherapy is likely to be prescribed more

Table 3 Odds ratio (OR) and 95\% confidence interval $(\mathrm{Cl})$ of sudden unexpected death in epilepsy in relation to lamotrigine treatment in women

\begin{tabular}{|c|c|c|c|c|c|}
\hline & No. cases & No. controls & Model $1^{\mathrm{a}}$ OR $(95 \% \mathrm{CI})$ & Model $2^{b}$ OR $(95 \% \mathrm{CI})$ & Model $3^{c}$ OR $(95 \% \mathrm{CI})$ \\
\hline No AEDs ${ }^{d}$ & 13 & 95 & 1 & 1 & 1 \\
\hline Other monotherapye & 36 & 156 & $1.48(0.73-2.99)$ & $1.19(0.53-2.65)$ & $0.68(0.23-2.06)$ \\
\hline Other polytherapy ${ }^{f}$ & 23 & 84 & $1.83(0.86-3.90)$ & $1.11(0.46-2.68)$ & $0.54(0.16-1.77)$ \\
\hline Lamotrigine monotherapyg & 12 & 53 & $1.52(0.64-3.61)$ & $1.24(0.46-3.32)$ & $0.67(0.18-2.52)$ \\
\hline Lamotrigine polytherapy $^{\text {h }}$ & 17 & 80 & $1.47(0.65-3.29)$ & $1.03(0.41-2.58)$ & $0.35(0.10-1.28)$ \\
\hline
\end{tabular}

AED = antiepileptic drug; GTCS = generalized tonic-clonic seizures.

a Model 1 is adjusted for matching variables (sex and calendar time) and age.

${ }^{b}$ Model 2 is adjusted for the same variables as model 1 together with duration and type of epilepsy, living conditions (sharing bedroom), intellectual disability, substance abuse, alcohol dependence, and education level.

c Model 3 is adjusted for the same variables as model 2 together with history of GTCS, GTCS frequency last year of observation, and nocturnal GTCS last year of observation.

d No AEDs in women dispensed within 90 days of death or index date.

e Other monotherapy than lamotrigine in women dispensed within 90 days of death or index date.

f Polytherapy not including lamotrigine in women dispensed within 90 days of death or index date.

g Lamotrigine monotherapy in women dispensed within 90 days of death or index date.

$\mathrm{h}$ Lamotrigine included in polytherapy in women dispensed within 90 days of death or index date. 
Table 4 Odds ratio (OR) and 95\% confidence interval (CI) of sudden unexpected death in epilepsy in relation to treatment with drugs other than antiepileptic drugs (yes/no)

\begin{tabular}{|c|c|c|c|c|c|}
\hline & Cases & Controls & Model $1^{\mathrm{a}}$ OR $(95 \% \mathrm{Cl})$ & Model $2^{\mathrm{b}}$ OR $(95 \% \mathrm{Cl})$ & Model $3^{\mathrm{c}}$ OR $(95 \% \mathrm{Cl})$ \\
\hline SSRIs & 24 & 90 & $0.88(0.53-1.48)$ & $0.68(0.39-1.18)$ & $0.65(0.31-1.36)$ \\
\hline Other antidepressants ${ }^{d}$ & 14 & 39 & $1.15(0.59-2.25)$ & $1.07(0.51-2.21)$ & $1.85(0.70-4.88)$ \\
\hline Neuroleptics & 32 & 61 & $2.03(1.27-3.25)$ & $1.09(0.65-1.82)$ & $0.89(0.45-1.77)$ \\
\hline Statins & 9 & 78 & $0.37(0.17-0.78)$ & $0.46(0.21-1.02)$ & $0.34(0.11-0.99)$ \\
\hline$\beta$-blockers & 27 & 106 & $1.00(0.61-1.63)$ & $0.93(0.54-1.59)$ & $1.69(0.81-3.55)$ \\
\hline
\end{tabular}

Abbreviations: GTCS = generalized tonic-clonic seizures; SSRI = selective serotonin reuptake inhibitor.

a Model 1 is adjusted for matching variables (sex and calendar time) and age.

${ }^{\mathrm{b}}$ Model 2 is adjusted for the same variables as model 1 together with duration and type of epilepsy, living conditions (sharing bedroom), intellectual disability, substance abuse, alcohol dependence, and education level.

'Model 3 is adjusted for same variables as model 2 together with history of GTCS, GTCS frequency last year of observation, and nocturnal GTCS last year of observation.

d Other antidepressants than SSRIs.

frequently to patients with severe epilepsy, including higher frequency of GTCS, this could confound the observed association. Consequently, polytherapy was no longer associated with an increased SUDEP risk when adjustment was made for GTCS frequency in the pooled analysis. ${ }^{7}$ However, the pooled analysis did not identify any protective effect of polytherapy. ${ }^{7}$ Nevertheless, our results are compatible with observations in a previous meta-analysis of placebo-controlled randomized trials investigating adjunctive AED treatment of pharmacoresistant epilepsy. ${ }^{10}$ In this meta-analysis, identifying 20 SUDEP cases (18 definite or probable), SUDEP was significantly less frequent in the group randomized to add-on with an AED at a presumed efficacious dose than in the add-on placebo group. ${ }^{10}$ In contrast to our present study, data on seizure control in relation to SUDEP occurrence were not available in the metaanalysis.

No AED was associated with an increased SUDEP risk, either before or after adjusting for covariates. The results of the less frequently used AEDs in this study, levetiracetam, oxcarbazepine, and topiramate, need to be interpreted cautiously given the smaller numbers and the corresponding wider CIs. Interestingly, levetiracetam was associated with reduced SUDEP risk as monotherapy even after adjusting for GTCS frequency and other covariates, with an OR of 0.10. To our knowledge, this finding has not been reported before. Levetiracetam has a mode of action different from other AEDs. Whether this relates to a possible effect on SUDEP risk remains to be explored. Other monotherapies, notably valproic acid, phenytoin, and oxcarbazepine, showed a nonsignificant trend for a reduced SUDEP risk, whereas topiramate showed a trend in the other direction, with an OR of 3.32 for increased SUDEP risk, which may warrant further investigation. Contrary to some other studies, we did not find an increased SUDEP risk in individuals taking carbamazepine ${ }^{3,4}$ or lamotrigine. ${ }^{5}$ One previous small case-control study suggested an increased SUDEP risk specifically among female patients treated with lamotrigine (mono- and polytherapy combined in the analysis), ${ }^{5}$ but no attempts were made to adjust for potential confounding factors in that study. This observation was not confirmed in the present study whether lamotrigine was used as monotherapy or in polytherapy.

Interestingly, we observed a reduced SUDEP risk with AED polytherapy after adjustment for GTCS frequency. This suggests that AED treatment may reduce the risk of SUDEP also through mechanisms beyond their ability to reduce the GTCS frequency. One possibility is that the severity or duration of the GTCS could be reduced, an effect that would not be captured by our methodology. Other potential mechanisms, in addition to AED effects on seizures, need to be considered. As an example, it cannot be excluded that people on polytherapy are more likely to be dependent and therefore kept under closer observation, which could lead to a reduced SUDEP risk, because supervision has been suggested to be protective. ${ }^{4}$

A retrospective cohort study from the United States used Medicaid claims data to evaluate adherence to treatment in more than 33,000 patients with AED prescriptions. ${ }^{11}$ Compared to adherence, nonadherence was associated with a more than threefold increase in mortality. In another large study in the United Kingdom, using similar methods to ours, nonadherence was associated with increased mortality. ${ }^{12}$ In both mentioned studies, the investigators analyzed all causes of mortality and not SUDEP specifically. The latter study used drug prescription as a measure of adherence. We used drug dispensing, which is one step closer to knowing whether the patient takes the medication. We observed an increased SUDEP risk among patients where time since last dispensed AED exceeded 180 days in model 2, indicating poor adherence or persistence with AED treatment. This increase was significant when adjusting for duration and type of epilepsy, living conditions, intellectual disability, substance abuse, alcohol dependence, and education, but not when adjustments also included frequency of GTCS and nocturnal GTCS. A possible explanation for this observation is that nonadherence can be expected to increase SUDEP risk through 
worsened control of GTCS, which in turn is a mediator to SUDEP, explaining that ORs are attenuated when adjusting for GTCS. Using physicians' mention of nonadherence in medical records yielded very similar risk estimates as the analysis based on drug dispensing, supporting the role of nonadherence as a risk factor for SUDEP. Although the validity of information in medical records on nonadherence is uncertain, ${ }^{23}$ the fact that both methods point in the same direction strengthens our conclusions.

It is conceivable that other medications than AEDs could affect SUDEP risk. Pharmacologic treatment has been tried successfully in prevention of sudden cardiac death in patients with coronary artery disease, postmyocardial infarction, structural heart disease, and congestive heart failure. ${ }^{24}$ Although this is a different population compared to patients with epilepsy and even if sudden cardiac death has a different pathophysiology, it is reasonable to consider the possibility of a preventive effect of drugs such as $\beta$-blockers and statins on SUDEP given the similarities of the final event. Atypical and typical antipsychotics have been shown to increase mortality, including sudden cardiac death. ${ }^{25}$ However, SUDEP risk has not been assessed in relation to SSRIs, $\beta$-blockers, statins, or neuroleptics. Preliminary data from people with epilepsy suggest that SSRIs are associated with reduced peri-ictal oxygen desaturation in focal seizures, but not in GTCS, ${ }^{26}$ and pretreatment with fluoxetine, an SSRI antidepressant, in an animal seizure model prevented postictal respiratory arrest and SUDEP. ${ }^{13}$ We did not find a lower risk of SUDEP with use of SSRIs or other antidepressants. This negative finding is in line with a study that did not find evidence that SSRIs protected against all-cause mortality in a large population-based cohort study of people with epilepsy, but we cannot exclude a protective effect of SSRIs given the limited number of exposed. ${ }^{27}$

We did not observe an increased or reduced SUDEP risk with concomitant use of neuroleptics or $\beta$-blockers. In our study, statin use was associated with a $66 \%$ reduced SUDEP risk even after adjusting for GTCS frequency. An association has been found between the use of statins and a reduced risk of developing epilepsy ${ }^{28}$ and intake of statins has been associated with reduced mortality in status epilepticus. ${ }^{29}$ There are also studies reporting statins to reduce the risk of sudden cardiac death, ${ }^{30}$ but ours is the first study to indicate a reduction in the risk of SUDEP.

The strengths of the study are the size, being the largest case-control study of SUDEP that we are aware of, and its population-based and nationwide design with cases and controls from the same population. Furthermore, all epilepsy cases and controls were validated, and we were able to examine all medical records for cases and for $97 \%$ of possible controls. Another strength was that we used data from the Swedish Prescribed Drug Register, which covers all prescriptions dispensed in pharmacies in Sweden, which is likely to be more accurate in terms of what the patient is realistically taking than information from patient records. To our knowledge, this methodology in combining extensive records review and registers has not been applied to this extent before in evaluating SUDEP risk. Given these strengths, our results are generalizable to other settings with similar socioeconomic and health care conditions.

Because this was an observational study, we cannot rule out confounding. As a strength, we had the opportunity to adjust for a range of potential risk factors for SUDEP, including living conditions and GTCS, previously shown to be associated with excess risk of SUDEP in this cohort. ${ }^{14}$ It seems unlikely that the reduced risk seen in individuals on polytherapy would be explained by remaining confounding, since this would require this patient group to have a higher frequency of an unknown protective factor. GTCS was included separately in the models because it may be a mediator in the association between AEDs and SUDEP; a protective effect of AED risk may be exerted by improved control of GTCS, and conversely, nonadherence may increase SUDEP risk because it is associated with lack of seizure control. ${ }^{31}$ Adjusting for GTCS frequency may therefore dilute an apparent effect of nonadherence on SUDEP risk. In our original analyses, we did not adjust for level of care. Interestingly, a recent retrospective cohort study from Canada reported that "exposure to specialist care is associated with incremental reductions in the hazards of premature mortality" among people with epilepsy. ${ }^{32}$ That study, however, assessed all-cause mortality and not SUDEP, and we could not observe any effect of level of care on the associations reported in our study.

Among the weaknesses are also that the authors extracting information were not blinded to the outcome, and were aware of previous reports on SUDEP risk factors, which may introduce bias. At the same time, the information was collected identically using a standardized protocol for both cases and controls. Our definitions of being on an AED and adherent (AED dispensed within 90 days of death or index date) could be too strict. It is conceivable that patients have accumulated medications over time and have not dispensed AEDs or other medications within 90 days of death or index date without being nonadherent. In addition, dispensing medication does not guarantee intake.

No AED, neither in mono- nor polytherapy, was associated with an increased risk for SUDEP. In contrast, polytherapy more specifically in combinations including lamotrigine, valproic acid, and levetiracetam was associated with reduced risk for SUDEP even after adjusting for GTCS and other covariates. The same applied to levetiracetam as monotherapy. Given the conflicting results with some previous reports, our data on polytherapy should be interpreted cautiously, although adding an AED to existing baseline AED treatment of patients with refractory seizures has been associated with a reduced SUDEP risk in the context of randomized controlled trials. ${ }^{10}$ Our data furthermore indicate that AEDs may lower the risk of SUDEP not just by reducing the frequency of GTCS and that treatment with statins may be protective. Efforts should be made to 
enhance medication adherence as this is likely to reduce SUDEP risk. Finally, our findings suggest that statins might be a suitable candidate for future research to identify SUDEP preventive interventions.

\section{Study funding}

The study was supported by funding from Stockholm County Council, GlaxoSmithKline, and Citizens United for Research in Epilepsy (CURE). The sponsors had no influence on the conduct of the study, analysis, interpretation, writing of the manuscript, or the decision to publish the results.

\section{Disclosure}

O. Sveinsson has received grants from GSK, personal fees from Biogen, and honoraria to his institution from Biogen and UCB for lectures and advisory board, outside the submitted work. T. Andersson and S. Carlsson report no disclosures. P. Mattsson received research support from the Uppsala County Council, CURE, Epilepsifonden, and Selander Foundation. T. Tomson is an employee of Karolinska Institutet, is associate editor of Epileptic Disorders, has received speaker's honoraria to his institution from Eisai, Sanofi, Sun Pharma, UCB, and Sandoz, and received research support from Stockholm County Council, EU, CURE, GSK, UCB, Eisai, and Bial. Go to Neurology.org/ $\mathrm{N}$ for full disclosures.

\section{Publication history}

Received by Neurology December 23, 2019. Accepted in final form June 18, 2020.

Appendix Authors

\begin{tabular}{lll}
\hline Name & Location & Contribution \\
\hline $\begin{array}{l}\text { Olafur } \\
\text { Sveinsson, } \\
\text { MD, PhD }\end{array}$ & $\begin{array}{l}\text { Karolinska } \\
\text { Institutet }\end{array}$ & $\begin{array}{l}\text { Major role in design of study and } \\
\text { acquisition of data, drafted the } \\
\text { manuscript for intellectual content }\end{array}$ \\
\hline $\begin{array}{l}\text { Tomas } \\
\text { Andersson, } \\
\text { BSc }\end{array}$ & $\begin{array}{l}\text { Karolinska } \\
\text { Institutet }\end{array}$ & $\begin{array}{l}\text { Statistical analysis, interpreted the data, } \\
\text { revised the manuscript for intellectual } \\
\text { content }\end{array}$ \\
$\begin{array}{l}\text { Peter } \\
\text { Mattsson, MD, } \\
\text { PhD }\end{array}$ & $\begin{array}{l}\text { University } \\
\text { of Uppsala }\end{array}$ & $\begin{array}{l}\text { Design of study, interpreted the data, } \\
\text { revised the manuscript for intellectual } \\
\text { content }\end{array}$ \\
\hline $\begin{array}{l}\text { Sofia Carlsson, } \\
\text { PhD }\end{array}$ & $\begin{array}{l}\text { Karolinska } \\
\text { Institutet }\end{array}$ & $\begin{array}{l}\text { Design of study, interpreted the data, } \\
\text { revised the manuscript for intellectual } \\
\text { content }\end{array}$ \\
$\begin{array}{l}\text { Torbjörn } \\
\text { Tomson, MD, } \\
\text { PhD }\end{array}$ & $\begin{array}{l}\text { Karolinska } \\
\text { Institutet }\end{array}$ & $\begin{array}{l}\text { Major role in design of study, interpreted } \\
\text { the data, revised the manuscript for } \\
\text { intellectual content }\end{array}$ \\
\hline
\end{tabular}

\section{References}

1. Thurman DJ, Hesdorffer DC, French JA. Sudden unexpected death in epilepsy: assessing the public health burden. Epilepsia 2014;55:1479-1485.

2. Harden C, Tomson T, Gloss D, et al. Practice guideline summary: sudden unexpected death in epilepsy incidence rates and risk factors: report of the Guideline Development, Dissemination, and Implementation subcommittee of the American
Academy of Neurology and the American Epilepsy Society. Neurology 2017;88: 1674-1680.

3. Timmings PL. Sudden unexpected death in epilepsy: a local audit. Seizure 1993;2: 287-290.

4. Langan Y, Nashef L, Sander JW. Case-control study of SUDEP. Neurology 2005;64: $1131-1133$.

5. Aurlien D, Tauboll E, Gjerstad L. Lamotrigine in idiopathic epilepsy: increased risk of cardiac death? Acta Neurol Scand 2007;115:199-203.

6. Tomson T, Hirsch LJ, Friedman D, et al. Sudden unexpected death in epilepsy in lamotrigine randomized-controlled trials. Epilepsia 2013;54:135-140.

7. Hesdorffer DC, Tomson T, Benn E, et al. ILAE Commission on Epidemiology (Subcommission on Mortality): do antiepileptic drugs or generalized tonic-clonic seizure frequency increase SUDEP risk? A combined analysis. Epilepsia 2012;53: 249-252.

8. Nilsson L, Farahmand BY, Persson P-G, Thiblin I, Tomson T. Risk factors for sudden unexpected death in epilepsy: a case-control study. Lancet 1999;353:888-893.

9. Walczak TS, Leppik IE, D'Amelio M, et al. Incidence and risk factors in sudden unexpected death in epilepsy: a prospective cohort study. Neurology 2001;56: 519-525.

10. Ryvlin P, Cucherat M, Rheims S. Risk of sudden unexpected death in epilepsy in patients given adjunctive antiepileptic treatment for refractory seizures: a metaanalysis of placebo-controlled randomised trials. Lancet Neurol 2011;10:961-968.

11. Faught E, Duh MS, Weiner JR, Guérin A, Cunnington MC. Nonadherence to antiepileptic drugs and increased mortality: findings from the RANSOM study. Neurology 2008;71:1572-1578.

12. Ridsdale L, Charlton J, Ashworth M, Richardson MP, Gulliford MC. Epilepsy mortality and risk factors for death in epilepsy: a population-based study. Br J Gen Pract 2011;61:e271-e278.

13. Tupal S, Faingold CL. Evidence supporting a role of serotonin in modulation of sudden death induced by seizures in DBA/2 mice. Epilepsia 2006;47;21-26.

14. Sveinsson $\mathrm{O}$, Andersson T, Mattsson P, Carlsson S, Tomson T. Clinical risk factors in SUDEP: a nationwide population-based case-control study. Neurology 2019;94:e419-e429.

15. Nashef L. Sudden unexpected death in epilepsy: terminology and definitions. Epilepsia 1997;38(11 suppl):6-8.

16. Annegers IF. United States perspective on definitions and classifications. Epilepsia 1997;38(11 suppl):9-12.

17. Ludvigsson JF, Andersson E, Ekbom A, et al. External review and validation of the Swedish national inpatient register. BMC Public Health 2011;11:450.

18. Johansson LA, Björkenstam C, Westerling R. Unexplained differences between hospital and mortality data indicated mistakes in death certification: an investigation of 1,094 deaths in Sweden during 1995. J Clin Epidemiol 2009;62:1202-1209.

19. Fisher RS, Cross JH, French JA, et al. Operational classification of seizure types by the international League against epilepsy: position paper of the ILAE commission for classification and terminology. Epilepsia 2017;58:522-530.

20. Scheffer IE, Berkovic S, Capovilla G, et al. ILAE classification of the epilepsies: position paper of the ILAE commission for classification and terminology. Epilepsia 2017;58:512-521

21. Wettermark B, Hammar N, Fored CM, et al. The new Swedish Prescribed Drug Register: opportunities for pharmacoepidemiological research and experience from the first six months. Pharmacoepidemiol Drug Saf 2007;16:726-735.

22. Vandenbroucke JP, Pearce N. Case-control studies: basic concepts. Int J Epidemiol 2012;41:1480-1489.

23. Verducci C, Hussain F, Donner E, et al. SUDEP in the North American SUDEP registry: the full spectrum of epilepsies. Neurology 2019;93:e227-e236.

24. Arshad A, Mandava A, Kamath G, Musat D. Sudden cardiac death and the role of medical therapy. Progr Cardiovasc Dis 2008;50:420-438.

25. Murray-Thomas T, Jones ME, Patel D, et al. Risk of mortality (including sudden cardiac death) and major cardiovascular events in atypical and typical antipsychotic users: a study with the general practice research database. Cardiovasc Psychiatry Neurol 2013;2013:247486.

26. Bateman LM, Li CS, Lin TC, Seyal M. Serotonin reuptake inhibitors are associated with reduced severity of ictal hypoxemia in medically refractory partial epilepsy. Epilepsia 2010;51:2211-2214.

27. Josephson CB, Gonzalez-Izquierdo A, Denaxas S, et al. Serotonin reuptake inhibitors and mortality in epilepsy: a linked primary-care cohort study. Epilepsia 2017;58 2002-2009.

28. Etminan M, Samii A, Brophy JM. Statin use and risk of epilepsy: a nested case-control study. Neurology 2010;75:1496-1500.

29. Sierra-Marcos A, Alvarez V, Faouzi M, et al. Statins are associated with decreased mortality risk after status epilepticus. Eur J Neurol 2015;22:402-405.

30. Beri A, Contractor T, Khasnis A, Thakur R. Statins and the reduction of sudden cardiac death: antiarrhythmic or anti-ischemic effect? Am J Cardiovasc Drugs 2010; 10:155-164.

31. Manjunath R, Davis KL, Candrilli SD, Ettinger AB. Association of antiepileptic drug nonadherence with risk of seizures in adults with epilepsy. Epilepsy Behav 2009;14: 372-378.

32. Lowerison MW, Josephson CB, Jetté N, et al. Association of levels of specialized care with risk of premature mortality in patients with epilepsy. JAMA Neurol 2019;76: $1352-1358$ 


\section{Neurology}

\section{Pharmacologic treatment and SUDEP risk: A nationwide, population-based, case-control study \\ Olafur Sveinsson, Tomas Andersson, Peter Mattsson, et al.}

Neurology 2020;95;e2509-e2518 Published Online before print September 23, 2020

DOI 10.1212/WNL.0000000000010874

This information is current as of September 23, 2020

\section{Updated Information \& Services}

References

Citations

Subspecialty Collections

Permissions \& Licensing

Reprints including high resolution figures, can be found at: http://n.neurology.org/content/95/18/e2509.full

This article cites 32 articles, 7 of which you can access for free at: http://n.neurology.org/content/95/18/e2509.full\#ref-list-1

This article has been cited by 2 HighWire-hosted articles: http://n.neurology.org/content/95/18/e2509.full\#\#otherarticles

This article, along with others on similar topics, appears in the following collection(s):

All Epilepsy/Seizures

http://n.neurology.org/cgi/collection/all_epilepsy_seizures

Antiepileptic drugs

http://n.neurology.org/cgi/collection/antiepileptic_drugs

Case control studies

http://n.neurology.org/cgi/collection/case_control_studies

Clinical trials Observational study (Cohort, Case control)

http://n.neurology.org/cgi/collection/clinical_trials_observational_stud y_cohort_case_control

Risk factors in epidemiology

http://n.neurology.org/cgi/collection/risk_factors_in_epidemiology

Information about reproducing this article in parts (figures,tables) or in its entirety can be found online at:

http://www.neurology.org/about/about_the_journal\#permissions

Information about ordering reprints can be found online:

http://n.neurology.org/subscribers/advertise

Neurology ${ }^{\circledR}$ is the official journal of the American Academy of Neurology. Published continuously since 1951, it is now a weekly with 48 issues per year. Copyright Copyright ( 2020 The Author(s). Published by Wolters Kluwer Health, Inc. on behalf of the American Academy of Neurology.. All rights reserved. Print ISSN: 0028-3878. Online ISSN: 1526-632X.

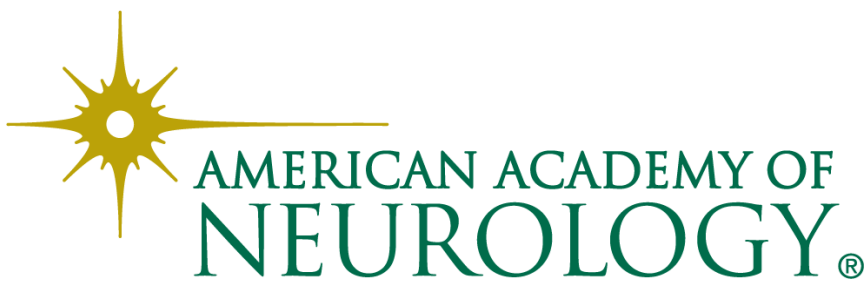

